\title{
Rate Independent and Rate Dependent Structural Evolution during Severe Plastic Deformation
}

\author{
Andrea Bachmaier*1, Martin Hafok*2 and Reinhard Pippan \\ Erich Schmid Institute, Austrian Academy of Sciences, Jahnstr. 12, A-8700 Leoben, Austria
}

\begin{abstract}
High pressure torsion (HPT) deformation enables the grain refinement of bulk materials until a saturation region is reached where no further microstructural refinement can be observed. The influence of deformation temperature, alloying and strain rate on the saturation region was examined by using pure aluminum, an Al-1 mass $\% \mathrm{Mg}$ alloy and an $\mathrm{Al}-3$ mass $\% \mathrm{Mg}$ alloy. The deformation temperature was varied between $-196^{\circ} \mathrm{C}$ and $450^{\circ} \mathrm{C}$. Both, temperature and alloying exhibit a pronounced influence on the saturation microstructure. The measurements reveal either a rate independent behavior of the structural evolution at low temperatures and a rate dependent behavior of the structural evolution at high temperatures. Two different processes are proposed to be the reason for the saturation at low and high homologous temperatures. [doi:10.2320/matertrans.MB200912]
\end{abstract}

(Received August 17, 2009; Accepted October 2, 2009; Published December 25, 2009)

Keywords: aluminium alloy, high pressure torsion, saturation, grain boundary migration, strain rate

\section{Introduction}

Severe plastic deformation (SPD) is well known to allow the grain refinement of bulk materials. An ultra fine grained or even nanocrystalline microstructure is formed by SPD with a high fraction of high-angle boundaries. ${ }^{1-4)}$ At strains larger than a critical value, no further microstructural refinement can be observed and a saturation region is reached which also manifests in a stagnation in hardening of the material. This general behaviour is independent of the material and the processing parameters in single phase materials. Only the minimum size of the crystallites in the saturation and the necessary strain to reach the saturation are influenced by the material. The initial process of fragmentation as well as the most important parameters influencing the grain refinement are well documented in literature. ${ }^{5-10)}$ The grain refinement process is especially influenced by the temperature, alloying, the strain rate and the deformation path. ${ }^{11)}$ Although these major parameters controlling the grain refinement are well known, there still exists no clear explanation for the question how an increasing strain can lead to a steady state in the microstructure and the hardening of a material. To maintain a saturation microstructure, a balance in the structural restoration process must be kept: the same number of dislocations have to be eliminated as produced by the applied strain. In addition, the annihilation and generation of boundaries have to be also in balance. The generation of new boundaries can be caused by a simple increase of boundary length due to an elongation of the grains and by the formation of new boundaries from dense dislocation walls. The reduction in boundary length requires a movement of boundaries.

At very large strains, when the saturation in strength and microstructural refinement is observed, it is evident that the generation and restore mechanisms are in equilibrium. However, the details of the phenomena are not well under-

\footnotetext{
${ }^{* 1}$ Corresponding author, E-mail: andrea.bachmaier@stud.unileoben.ac.at

${ }^{* 2}$ Present address: Boehler Edelstahl GmbH\&Co KG, 8605 Kapfenberg, Austria
}

stood. Temperature and alloying should affect the processes significantly. Therefore both parameters are varied in a wide range in an $\mathrm{Al}$ alloy.

In this study, we used aluminium, an $\mathrm{Al}-1$ mass $\% \mathrm{Mg}$ alloy and an Al-3 mass $\% \mathrm{Mg}$ alloy in order to investigate the influences of deformation temperature, alloying and strain rate on the saturation region during HPT deformation. The low melting temperature of the $\mathrm{Al}$ alloy allows the deformation at homologous temperatures ranging from $0.1-$ $0.8 T_{\mathrm{m}}\left(T_{\mathrm{m}}\right.$ being the melting temperature).

\section{Experimental}

Samples for HPT deformation were cut out of an aluminium (99.99\% purity), an Al-1 mass $\% \mathrm{Mg}$ and an Al3 mass $\% \mathrm{Mg}$ alloy plate. A detailed description of the HPT equipment used for processing the materials present in this paper is given in Ref. 6). The disk-shaped specimens with a diameter of $14 \mathrm{~mm}$ and a height of approximately $0.8 \mathrm{~mm}$ are pressed between two anvils, which can be heated or cooled to allow SPD at temperatures between $-196^{\circ} \mathrm{C}$ and $500^{\circ} \mathrm{C}$. Furthermore, the rotation speed of the anvils can be varied over a wide range. The direct measurement of the torque applied to the sample is also possible, which can be used to estimate the change in the flow stress of the material in-situ during deformation.

The shear strain can be calculated according to $\gamma=\frac{2 \pi n}{t} r$ whereby $r, n, t$ are the distance from the center of the sample, the number of revolutions and the thickness of the sample, respectively. As the strain is dependent on the radius, all strains and strain rates were calculated for a radius of $6 \mathrm{~mm}$. The thickness $t$ is calculated according to $t=\left(t_{\mathrm{i}}+t_{\mathrm{a}}\right) / 2$ whereby $t_{\mathrm{i}}$ and $t_{\mathrm{a}}$ are the thickness of the sample before and after the deformation, respectively.

The HPT deformation was performed in three different ways: First of all the deformation was performed at constant, but different temperatures ranging from $-196^{\circ} \mathrm{C}$ to $450^{\circ} \mathrm{C}$ with the rotation speed kept constant. In addition to the constant temperature experiments, cooling experiments were performed. The samples were heated up and kept 
(a)

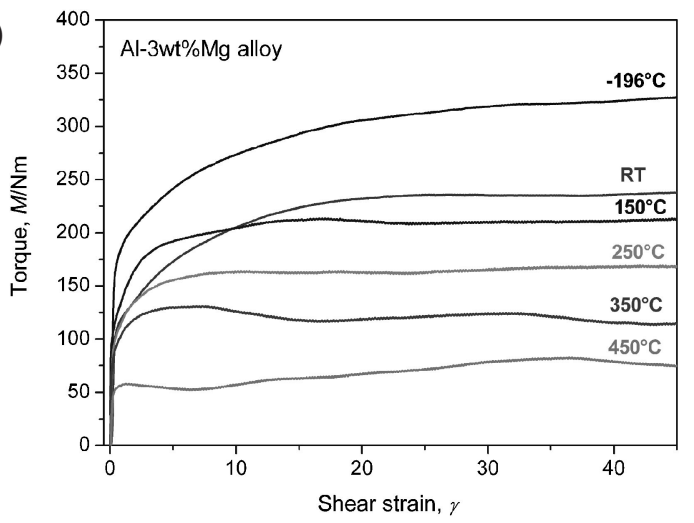

(b)

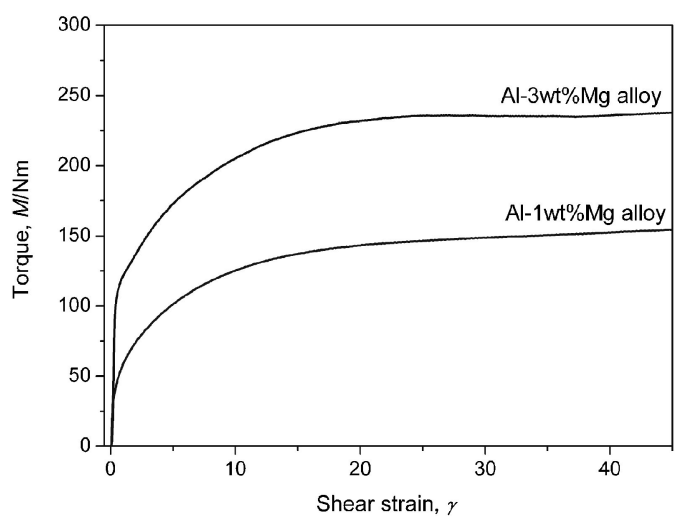

Fig. 1 (a) In-situ torque measured during the deformation of the Al-3 mass $\% \mathrm{Mg}$ alloy vs. the shear strain at a strain rate of $0.4 \mathrm{~s}^{-1}$ $(0.48 \mathrm{rpm})$. The deformation temperature was varied between $-196^{\circ} \mathrm{C}$ and $450^{\circ} \mathrm{C}$. (b) Comparison between the in-situ torques measured during the deformation of the $\mathrm{Al}-1$ mass $\% \mathrm{Mg}$ and $\mathrm{Al}-3$ mass $\% \mathrm{Mg}$ alloy at room temperature. The strain rate during deformation was $0.4 \mathrm{~s}^{-1}(0.48 \mathrm{rpm})$.

at a constant temperature of $450^{\circ} \mathrm{C}$ for about $5 \mathrm{~min}$. Afterwards, the deformation with constant, but different rotation speeds was started until a constant torque was measured. Subsequently, the heating device was turned off and the sample cooled down during continued deformation. During the cooling of the sample the change in torque was measured. Additionally, similar experiments during heating from cryogenic temperatures were performed. In the third set of experiments, the samples were heated to constant, but different temperatures between $-196^{\circ} \mathrm{C}$ and $450^{\circ} \mathrm{C}$. Afterwards the HPT deformation was started with a high rotation speed $(0.48 \mathrm{rpm})$ until a constant torque was measured. During the ongoing deformation, the rotation speed was immediately decreased to the lowest possible rotation speed $(0.016 \mathrm{rpm})$ and the change of the torque was measured.

Microstructures were characterized in a scanning electron microscope (SEM) type LEO 1525 using back scattered electrons (BSE) and the microtexture was investigated by electron back scatter diffraction (EBSD) using the EBSD system attached to the SEM. The micrographs were taken at radii of approximately $6 \mathrm{~mm}$ on the shear plane of the sample (see Fig. 3). Grain size determination was performed on BSE micrographs. Vickers microhardness measurements were performed with a BUEHLER Mircomet 5100 using a load of $500 \mathrm{~g}$.

\section{Results}

\subsection{Influence of deformation temperature}

The influence of the deformation temperature on the saturation region was examined in HPT deformation experiments at different but constant temperatures.

The torque applied during the HPT deformation of the Al-3 mass $\% \mathrm{Mg}$ alloy versus the applied strain is shown in Fig. 1(a). The strain is calculated for a radius of $6 \mathrm{~mm}$. The HPT deformation was conducted with a constant rotation speed $(0.48 \mathrm{rpm})$. The alloy was deformed at $-196^{\circ} \mathrm{C}$, room temperature, $150^{\circ} \mathrm{C}, 250^{\circ} \mathrm{C}, 350^{\circ} \mathrm{C}$ and $450^{\circ} \mathrm{C}$ until a constant torque was measured indicating that the saturation region was reached. Because the measured torque can be influenced by several experimental parameters, the same experimental conditions were used for these experiments to make a comparison of the measured torque feasible.

All recorded torque curves show a similar behavior: at low strains the torque increases until at a certain shear strain a saturation torque is reached. It can be clearly seen that the deformation temperature affects the saturation torque and the onset strain of saturation of the Al-3 mass $\% \mathrm{Mg}$ alloy. Increasing the deformation temperature lowers the saturation torque and the saturation shear strain.

Figure 1(b) compares the applied torque during HPT deformation of the Al-1 mass $\% \mathrm{Mg}$ alloy and the Al3 mass $\% \mathrm{Mg}$ alloy at room temperature. The effect of alloying can be clearly seen: Deformed at room temperature, the Al1 mass $\% \mathrm{Mg}$ alloy exhibits a significantly lower saturation torque than the Al-3 mass $\% \mathrm{Mg}$ alloy.

Figure 2 shows the development of the saturation microstructure of the Al-3 mass $\% \mathrm{Mg}$ alloy samples. BSE micrographs of the $\mathrm{Al}-3$ mass $\% \mathrm{Mg}$ alloy deformed at $-196^{\circ} \mathrm{C}$, $200^{\circ} \mathrm{C}, 300^{\circ} \mathrm{C}$ and $450^{\circ} \mathrm{C}$ at a strain rate of $0.2 \mathrm{~s}^{-1}$ (rotation speed: $0.25 \mathrm{rpm}$ ) were recorded. For all samples, the applied strain and the deformation conditions were chosen for the microstructure to be in the saturation regime. It is evident that the steady-state size of the structural elements increases with increasing temperature. The first micrograph show a sample which was deformed at $-196^{\circ} \mathrm{C}$. It shows elongated grains, which are aligned in tangential direction. This direction coincides with the shear direction during the HPT deformation. The average size of the structural elements is approximately $120 \mathrm{~nm}$ in the tangential direction and about $70 \mathrm{~nm}$ in the direction of the torsion axis. With rising temperature the size of the structural element increases and a change in the microstructure occurs. The grains become more equiaxed and the alignment in the tangential direction loses its significance. At $450^{\circ} \mathrm{C}$, a more or less equiaxed microstructure can be observed and a further increase in the size of the structural element with increasing temperature is measured. Furthermore, the grain boundaries become more defined at higher temperatures. The transition between these two kinds of morphologies occurs in a temperature range between $300^{\circ} \mathrm{C}$ and $350^{\circ} \mathrm{C}$. 

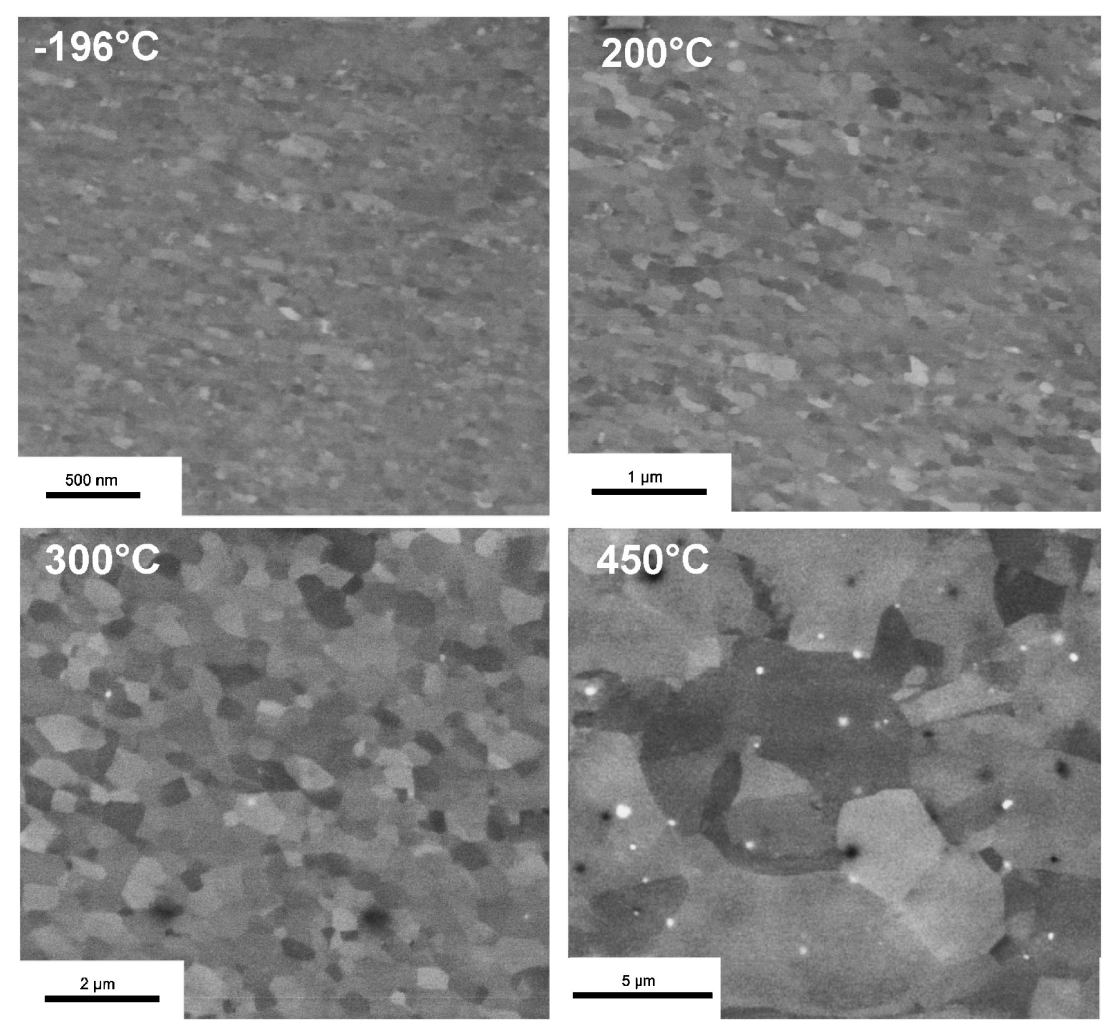

Fig. 2 Microstructure on the shear plane of the $\mathrm{Al}-3$ mass $\% \mathrm{Mg}$ alloy samples deformed at $-196^{\circ} \mathrm{C}, 200^{\circ} \mathrm{C}, 300^{\circ} \mathrm{C}$ and $450^{\circ} \mathrm{C}$ at a strain rate of $0.2 \mathrm{~s}^{-1}(0.25 \mathrm{rpm})$.
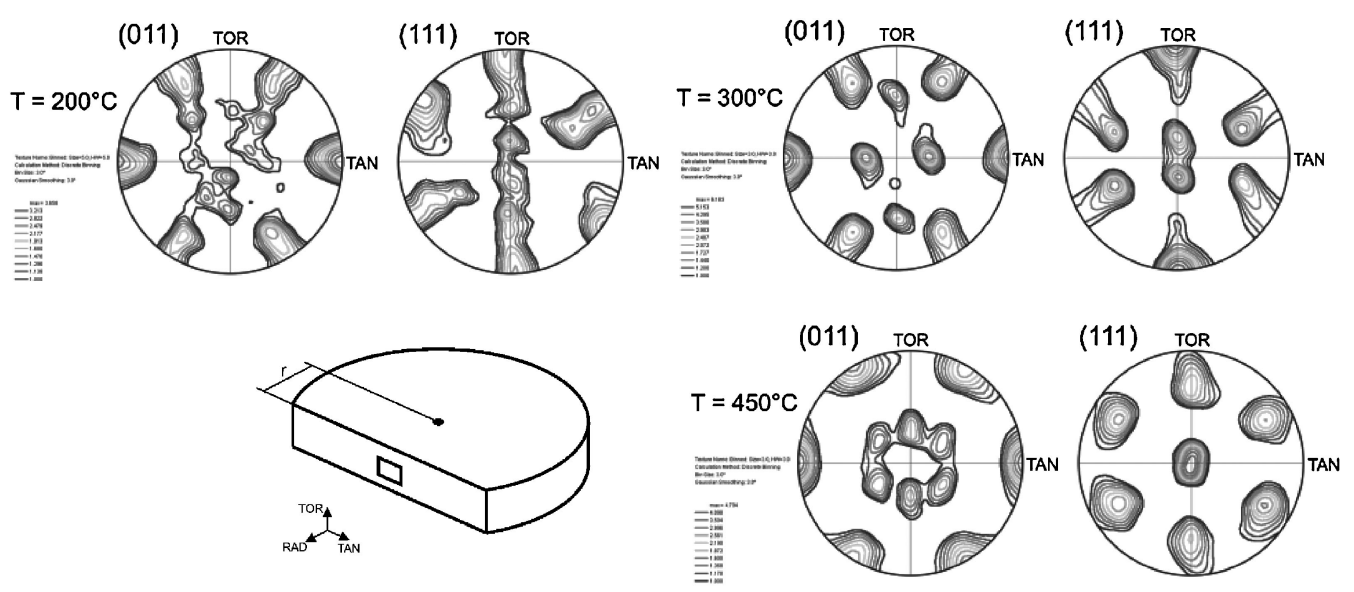

Fig. 3 Microtexture recorded in the center of the cut plane at a radius of $6 \mathrm{~mm}$ of the $\mathrm{Al}-3$ mass $\% \mathrm{Mg}$ alloy samples deformed at $200^{\circ} \mathrm{C}$, $300^{\circ} \mathrm{C}$ and $450^{\circ} \mathrm{C}$ at a strain rate of $0.2 \mathrm{~s}^{-1}(0.25 \mathrm{rpm})$. The direction of observations is also shown as an inset. The axes are denoted as TOR, RAD and TAN for the torsion, radial and tangential direction.

Figure 3 shows the development of the microtexture of the $\mathrm{Al}-3 \mathrm{mass} \% \mathrm{Mg}$ alloy samples deformed at $200^{\circ} \mathrm{C}, 300^{\circ} \mathrm{C}$ and $450^{\circ} \mathrm{C}$ at the same strain rate as used before. Considerable differences in the obtained microtexture can be observed. The pole figure of the sample deformed at $200^{\circ} \mathrm{C}$ shows a shear texture which is typical for HPT, but also comparable to face-centered cubic (fcc) materials that underwent cold deformation. ${ }^{12)}$ The microtexture becomes considerably pronounced at $300^{\circ} \mathrm{C}$ and a certain alignment of the crystal system with respect to the deformation state is apparent. The torsion axis lays parallel to the (111) glide plane and the [011] glide direction is aligned in the shear direction. On the contrary, the pole figure of the sample deformed at $450^{\circ} \mathrm{C}$ shows a different microtexture where the glide plane changes from the (111) to the (112) plane.

Figure 4 summarizes the development of the size of the structural elements and the measured microhardness as function of the deformation temperature for both aluminium alloys. The microhardness of the Al-3 mass $\% \mathrm{Mg}$ alloy samples decreases with increasing deformation temperature. The sample deformed at $-196^{\circ} \mathrm{C}$ exhibits the highest hardness values of $1.75 \mathrm{GPa}$, whereas the lowest hardness values of $0.67 \mathrm{GPa}$ were measured for the sample deformed at $450^{\circ} \mathrm{C}$. At room temperature the microhardness of the $\mathrm{Al}-$ 3 mass $\% \mathrm{Mg}$ alloy is about $1.48 \mathrm{GPa}$. Compared to the $\mathrm{Al}-$ 3 mass\% Mg alloy sample, the $\mathrm{Al}-1$ mass\% $\mathrm{Mg}$ alloy sample 


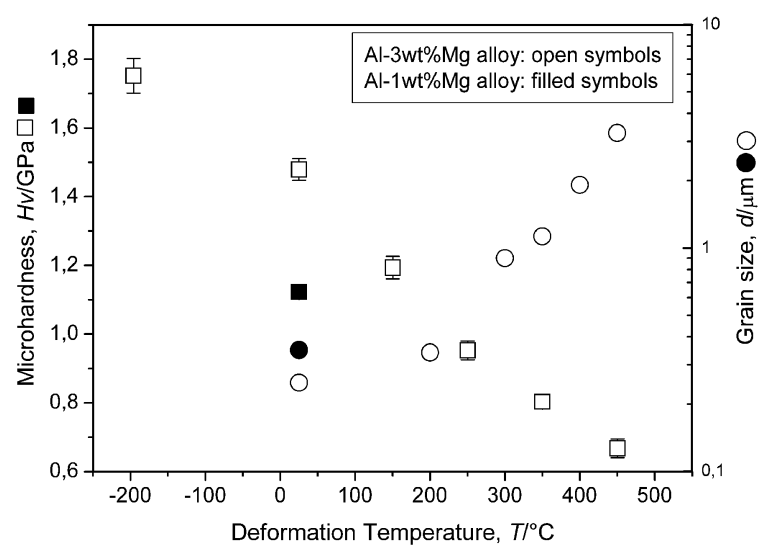

Fig. 4 Microhardness $\mathrm{Hv}$ and size of structural elements after HPT deformation of the Al-3 mass $\% \mathrm{Mg}$ alloy at different temperatures and of the $\mathrm{Al}-1$ mass $\% \mathrm{Mg}$ alloy at room temperature determined from BSE micrographs.

deformed at room temperature shows a lower microhardness $(1.13 \mathrm{GPa})$. The microhardness values are in good accordance with the determined size of the structural elements: With decreasing deformation temperature the size of the structural elements is reduced whereas the determined size of the structural elements of the Al-1 mass $\% \mathrm{Mg}$ sample deformed at room temperature is clearly larger than those of the Al-3 mass\% Mg alloy sample.

\subsection{Influence of strain rate}

To investigate the influence of the strain rate on the saturation region during HPT deformation, experiments with different rotational speeds $(0.05 \mathrm{rpm}-0.50 \mathrm{rpm})$ were performed as well.

During cooling and heating experiments, the influence of the strain rate in a temperature range from $-196^{\circ} \mathrm{C}$ to $450^{\circ} \mathrm{C}$ for the Al-3 mass $\% \mathrm{Mg}$ alloy and for comparison, of pure aluminium was examined. In Fig. 5(a) the results of the torque measurements are shown. With increasing temperature the measured torque and therefore, the flow stress of both materials decreases. Comparing the alloy and the pure aluminium, the measured torque for pure aluminium is lower. At room temperature, the aluminium alloy shows only a low strain rate sensitivity. Between room temperature and $450^{\circ} \mathrm{C}$, the $\mathrm{Al}$ alloy exhibits a certain strain rate sensitivity. Figure $5(\mathrm{~b})$ shows the microstructure of Al-3 mass $\% \mathrm{Mg}$ alloy samples deformed at $200^{\circ} \mathrm{C}$ at two different rotation speeds $(0.05 \mathrm{rpm}$ and $0.50 \mathrm{rpm})$. It can be clearly seen that an increase in strain rate leads to a smaller size of the structural elements in the saturation region. Nevertheless the effect of the strain rate on the saturation size of the structural elements is less pronounced than the effect of the deformation temperature.

Furthermore the aluminium alloys were HPT deformed at different deformation temperatures, but now the rotation speed was directly changed during the deformation. In the beginning, the samples were deformed with the highest possible rotation speed until saturation in the measured torque curve was observed. Afterwards, the rotation speed was abruptly changed from $0.48 \mathrm{rpm}$ to $0.016 \mathrm{rpm}$ and changes in the measured torque curves were directly recorded. Figure 6(a) shows the results of these measurements. The fluctuation of the torque is due to the inaccuracy of the alignment of the HPT tool.

For the samples deformed at room temperature and $-196^{\circ} \mathrm{C}$ no change in the measured torques were recorded at the moment of reducing the strain rate. The drop in the torque of the sample deformed at $-196^{\circ} \mathrm{C}$ results from a short unscheduled stop of the rotation at the time of the strain rate shifting. Moreover, the strain rate sensitivity at higher temperatures could be further confirmed in this experiment. Changing the strain rate during the deformation at $150^{\circ} \mathrm{C}$ and $250^{\circ} \mathrm{C}$ leads to a significant decline in the measured torques. The torque increases somewhat until a constant torque is measured again after a short time. The same behaviour can (a)

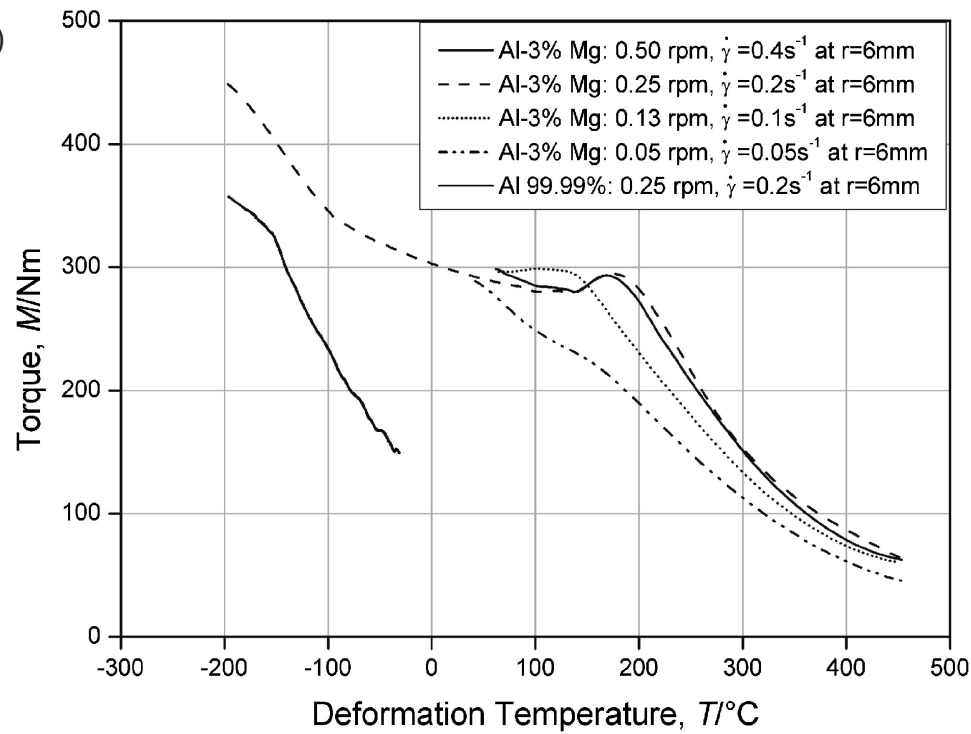

(b)

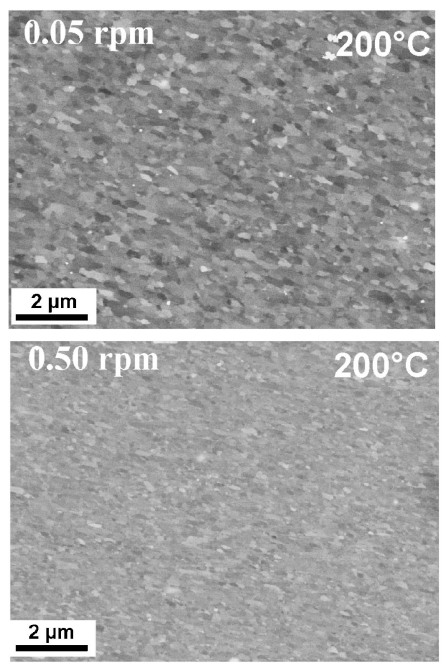

Fig. 5 (a) In-situ torque measured during cooling and heating experiments at different rotation speeds ranging from $0.05 \mathrm{rpm}$ to $0.50 \mathrm{rpm}$ (strain rate of $0.05 \mathrm{~s}^{-1}$ to $0.4 \mathrm{~s}^{-1}$ ). (b) BSE micrographs showing the microstructure of the $\mathrm{Al}-3 \mathrm{mass} \% \mathrm{Mg}$ alloy deformed at $200^{\circ} \mathrm{C}$ at two different rotation speeds. 
(a)

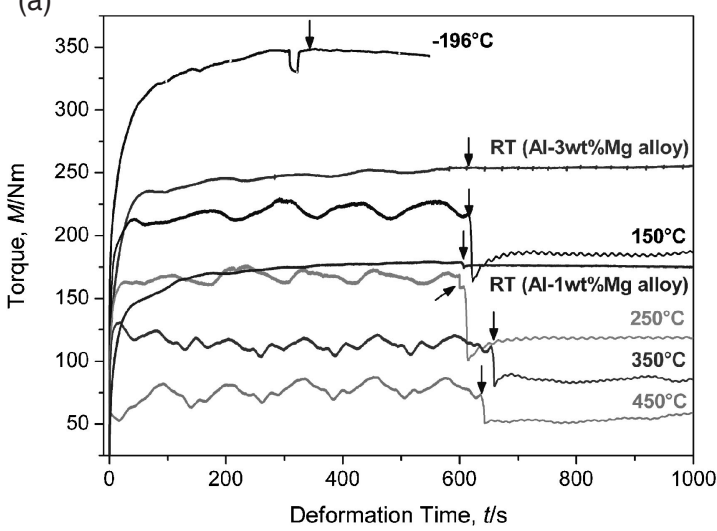

(b)

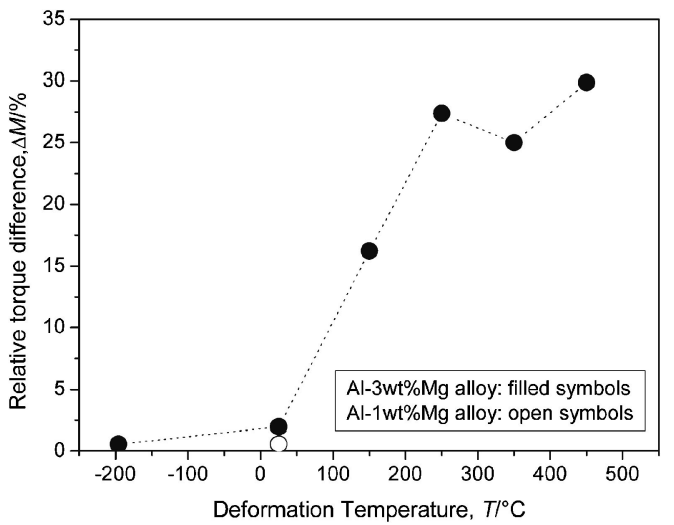

Fig. 6 (a) In-situ torque curves measured during the deformation of the Al-3 mass $\% \mathrm{Mg}$ alloy at different temperatures. The in situ-torque curve of the Al-1 mass $\% \mathrm{Mg}$ alloy which experiences the same strain rate variation is also shown. The times of rotation speed shifting are indicated by an arrow. (b) Relative torque difference $\Delta M=\left(M_{2}-M_{1}\right) /\left(M_{1}\right)$ for the two different strain rates as function of the deformation temperature of the Al-1 mass $\% \mathrm{Mg}$ alloy and the Al-3 mass $\% \mathrm{Mg}$ alloy. $M_{1}$ and $M_{2}$ are the measured torques for the high $(0.48 \mathrm{rpm})$ and low rotation speed $(0.016 \mathrm{rpm})$, respectively.

be observed during the deformation at $350^{\circ} \mathrm{C}$ and $450^{\circ} \mathrm{C}$, although the drop in the measured torques is less pronounced at higher temperatures. Similar shapes of the flow curves by the time of strain rate changes in the steady state flow regime are found in conventional hot working as well. We assume a similar process in the case of HPT deformation at elevated temperatures, although the accurate processes are not completely clear and require further research. Figure 6(b) compares the relative steady state torques differences $(\Delta M)$ as function of the different deformation temperatures for both strain rates. $\Delta M$ is calculated according to $\Delta M=\left(M_{2}-\right.$ $\left.M_{1}\right) /\left(M_{1}\right)$ whereby $M_{1}$ and $M_{2}$ are the measured steady state torques at the high and low rotation speeds, respectively. Comparing $\Delta M$, a decrease of the strain rate has hardly an influence on the steady state torque at room temperature and lower temperatures, but the influence of the strain rate increases significantly at higher deformation temperatures.

\section{Discussion}

In general, all investigated deformation conditions yield to a saturation of both, the structural element size and the flow stress, at large applied strains. The deformation temperature is one major parameter affecting the final size of the structural elements in the saturation. With decreasing deformation temperature, the size of the structural elements continuously decreases. Moreover, the deformation temperature influences the amount of strain which must be applied to reach the saturation regime and the saturation torque itself. Both parameters distinctly decrease with increasing deformation temperature. Similar behavior is also found in conventional hot working. ${ }^{13-15)}$

The second important parameter affecting the size of the structural elements in the saturation and the saturation torque is alloying. It causes significant reduction of the saturation size of the structural elements and therefore leads to an increase in the saturation torque.

Another parameter which has an effect on the saturation torque is the strain rate. Nevertheless, the experiments have shown that the saturation torque is influenced by the strain rate only in a certain temperature region. In deformation experiments at and below room temperature nearly no strain rate sensitivity is observed. In contrast to the low strain rate sensitivity at low temperatures, an enhanced strain rate sensitivity is observed at deformation temperatures ranging from room temperature to approximately $450^{\circ} \mathrm{C}$. In the whole strain rate sensitive regime, the strain rate has also an effect on the size of the structural elements whereby an increase of the strain rate results in a smaller size of the structural elements.

Furthermore, the microstructural investigations indicated a definite change in the morphology of the saturation microstructure depending on the deformation temperature. The microstructure consists of elongated grains aligned in the shear direction however with certain inclination at low deformation temperatures. This shape of the grains is maintained up to a deformation temperature of approximately $300^{\circ} \mathrm{C}$. At higher deformation temperatures, a completely different morphology of the microstructure develops. The shape of the grains is now equiaxed and no explicit alignment in any direction can be observed. Increasing deformation temperature not only alters the microstructural features, it also changes the microtexture in the saturation region. At low deformation temperatures, the typical shear texture after HPT deformation is received. This texture is similar to those obtained for fcc materials after cold deformation. ${ }^{12)}$ At higher deformation temperatures, the texture becomes more pronounced whereby the torsion axis is parallel to the glide plane (111) and the shear direction lays in the direction of the glide direction [110]. If the deformation temperature is further increased, the glide plane changes from (111) to the (112) plane, but the glide direction remains unchanged.

To maintain a steady state during continuous HPT deformation a mechanism for the elimination of dislocations must exist because new dislocations are constantly produced as long as an external strain is applied. In hot working, a steady state can be reached by dynamic recrystallization which is a diffusion-controlled process enhanced by temperature. $^{8,15-17)}$ 
Based on the in situ measurements of the torque curves, the microstructural and the microtextural investigations, we assume that two different processes active at low and high temperatures enable the steady state during HPT deformation.

At high temperatures we assume that a certain type of dynamic recrystallization ${ }^{18,19)}$ is responsible for the occurrence of the observed steady state at large strains. In general, boundaries are mobile and annihilate each other which finally lead to an equiaxed microstructure with mainly high-angle boundaries. Although the exact processes governing the movement of the boundaries are not clear in the case of HPT deformation, the driving force for the boundary migration seems be the reduction of the density of dislocations and the rate determining step the mobility of the boundaries. Because dynamic recrystallization is a diffusion-controlled process, it is enhanced by deformation at high homologous temperatures and influenced by the strain rate as well. The temperature dependence of the size of the structural elements in the saturation, the strain rate sensitivity and influence of the deformation temperature on the onset of the steady state during HPT deformation at high homologous temperatures would encourage this assumption. The morphology of the grains and the microtextural change in the saturation region at high deformation temperatures corroborates this further.

At low temperatures, we assume a process similar to dynamic recrystallization to maintain the steady state. In ultrafine grained and nanocrystalline metals, stress-induced grain boundary migration is proposed as an alternative plasticity mechanism at ambient and low temperatures. ${ }^{20-22)}$ Although there exists a certain temperature dependence, the influence of the deformation temperature is not as high as in the high temperature regime. Furthermore there exists hardly any strain rate sensitivity. The driving force for the boundary migration in this case does not seem to be the reduction of dislocation density, but rather stress induced by means of the external applied strain and strain induced through the stress field of the dislocations. Due to the reduced thermal mobility, the formation of an equiaxed microstructure is not possible.

\section{Conclusion}

In the present paper, the influence of the deformation temperature and the strain rate on the saturation region during severe plastic deformation were examined by deforming aluminium alloys at homologous temperatures ranging from $0.1-0.8 \mathrm{Tm}$.

The results are summarized as followed:

(1) HPT deformation of aluminium alloys leads to a steady state for all investigated deformation conditions.

(2) Deformation temperature and alloying are the two major parameters influencing the minimum size of the structural elements in the saturation and the onset of the steady state.

(3) The measurements reveal either a rate independent or a rate dependent behavior of the structural evolution depending on the temperature during deformation.

(4) A process similar to dynamic recrystallization is proposed to be the reason for the steady state at high homologous deformation temperatures. At low homologous deformation temperatures a typical severe plastic deformation behavior is observed, where the maintenance of the steady state is facilitated by stress and strain induced boundary migration.

\section{Acknowledgement}

The financial support by the Austrian Fonds zur Förderung der wissenschaftlichen Forschung (Project number: S10402N16) is gratefully acknowledged.

\section{REFERENCES}

1) M. J. Zehetbauer and R. Z. Valiev: Nanomaterials by Severe Plastic Deformation, (Wiley-VCH, Weinheim, Germany, 2004).

2) R. Z. Valiev, R. K. Islamgaliev and I. V. Alexandrov: Prog. Mater. Sci. 45 (2000) 103-189.

3) T. C. Lowe and R. Z. Valiev: JOM 56 (2004) 64-68.

4) Y. T. Zhu and T. G. Langdon: JOM 56 (2004) 58-63.

5) T. Hebesberger, H. P. Stüwe, A. Vorhauer, F. Wetscher and R. Pippan: Acta Mater. 53 (2005) 393-402.

6) A. Vorhauer, S. Kleber and R. Pippan: Mater. Sci. Eng. 281 (2005) 410-411.

7) A. Vorhauer, W. Knabl and R. Pippan: Mater. Sci. Forum 426-432 (2003) 2747.

8) N. Hansen: Metall. Mater. Trans. 32A (2001) 2917.

9) N. Hansen and D. Kuhlmannnn-Wilsdorf: Mater. Sci. Eng. 81 (1986) 141.

10) E. Schafler and R. Pippan: Mater. Sci. Eng. A 387-389 (2004) 799.

11) R. Pippan, F. Wetscher, M. Hafok, A. Vorhauer and I. Sabirov: Adv. Eng. Mater. 8 (2006) 1046.

12) G. R. Canova, U. F. Kocks and J. J. Jones: Acta Metall. 32 (1984) 211.

13) H. P. Stüwe: Proc. Conf. Deformation Under Hot Working Conditions, (The Iron and Steel Institute, London, 1968) 2-6.

14) Y. Zhang, X. Zeng, C. Lu and W. Ding: Mat. Sci. Eng. A 428 (2006) 91-97.

15) F. J. Humphreys and M. Hatherly: Recrystallization and Related Annealing Phenomena, (Elsevier, United Kingdom, 2004).

16) R. Sandstorm and R. Lagneborg: Acta Metall. 23 (1975) 387.

17) W. Roberts and B. Ahlborn: Acta Metall. 26 (1978) 801.

18) M. E. Kassner and S. Barrabas: Mater. Sci. Eng. A 410-411 (2005) $152-155$.

19) S. Gourdet and F. Montheillet: Mater. Sci. Eng. A 283 (2000) 274288.

20) M. Legros, D. S. Gianola and K. J. Hemker: Acta Mater. 56 (2008) 3380-3393.

21) F. Mompiou, D. Caillard and M. Legros: Acta Mater. 57 (2009) 2198-2209.

22) D. Caillard, F. Mompiou and M. Legros: Acta Mater. 57 (2009) 2390-2402. 